\title{
COVID-19 PANDEMIC: BIG DATA EMPOWERING HEALTH BUT THE PRIVACY CONCERNS
}

\author{
Neha Bhatt \\ Department: school of computing Graphic Era University \\ Vinod Chandra Joshi \\ Department of Management, Graphic Era University
}

\begin{abstract}
A B S T R A C T - In view of the information of the World Health Organization (WHO), Since December 2019, a group of instances of pneumonia has been accounted for in Wuhan, China. A tale coronavirus was in the end recognized and World Health Organization (WHO) incidentally named this new infection like the 2019 novel coronavirus (2019-nCoV). On 11 February 2020, the World Health Organization (WHO) authoritatively named the malady coronavirus ailment (COVID-19). The COVID-19 plague is spreading everywhere throughout the reality where huge information has a fundamental job to battle against COVID-19 through which we get day by day refreshes about instances of the infection everywhere throughout the world. The expectation and anticipation for the infection needs bunch of information so legislatures of the world began the assortment. In setting to Indian government, they are gathering information of tainted individuals, travel history of open has been seen and for the following of open portable applications are been created. The progressive system of the information assortment for contaminated is start with crown testing fixates in each region on each state. Testing focuses are the base of the data that help government to investigate the contamination on the ground level. These assets move information to the service of wellbeing and family government assistance. Information assortment of movement history of individuals is being gathered by the service of flight. Enormous information accompanied the mesh unrest; however, it raises a worry of protection for individuals. In this pandemic, nations and their administrations are sufficiently able to gather and access their own information which open would not like to share prior.
\end{abstract}

KEYWORDS - Big data, Covid-19, Data Privacy, Empowering Health

\section{INTRODUCTION}

The days prior to the coronavirus appear to be light-years away, and it is hard not to feel nostalgic for life before COVID-19. In view of the information of World Health Organisation (WHO), Since December 2019, a bunch of instances of pneumonia have been accounted for in Wuhan, China. A tale coronavirus was in the long run distinguished and World Health Organization (WHO) briefly named this new infection as the 2019 novel coronavirus (2019-nCoV). On 11 February 2020, the WHO authoritatively named the infection as coronavirus ailment (COVID-19).[11] The COVID-19 scourge is spreading everywhere throughout the reality where the enormous information has crucial job to battle against COVID-19 through which we get day by day update about instances of infection in everywhere throughout the world. The points of interest we are having today in the battle against COVID-19 Pandemic that was not as modern in the SARS flare-up of 2003 is enormous information and the degree of innovation accessible. China took advantage of computerized instruments like large information, AI, and others as the infection spread through the country so as to contain and follow the episode. The exercises realized there have kept on battling the spread of the infection and utilize advanced innovation to grow constant gauges and it arm government chiefs and social insurance experts with intel they can use to foresee the effect of the COVID-19 Pandemic. The expectation and anticipation for the infection needs bunch of information so administrations of the world began the assortment. In setting to Indian government, they are gathering information of tainted individuals, travel history of open has been seen and for the following of open versatile applications are been created. The progression of the information assortment for contaminated is start with crown testing focuses in each region on each state. Testing focuses are the base of the data that help government to dissect the contamination on the ground level. These assets move information to the service of wellbeing and family government assistance. Information assortment of movement history of individuals is being gathered by the service of avionics. Huge information accompanied the mesh upset, yet it raises a worry of protection for individuals. In this pandemic, nations and their administrations are actually sufficiently able to gather and access their own information which open wouldn't like to share prior.

\subsection{Empowering Health with big data}

The spread of COVID-19 and the open's craving for data has started the making of open-source informational indexes and representations, making ready for an order presented as pandemic investigation. India's battle against the coronavirus is an innovative fight, on account of the nation's vanguard programming administrations industry. Government 


\section{International Journal of Engineering Applied Sciences and Technology, 2020 Vol. 5, Issue 4, ISSN No. 2455-2143, Pages 186-190 \\ Published Online August 2020 in IJEAST (http://www.ijeast.com)}

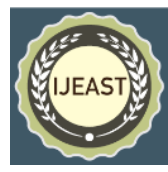

specialists are procuring its fullest potential in battling a pandemic that has contaminated 56,342 individuals up until this point.

Innovation designers are working dangerously fast for arrangements, making authorities at the state-run strategy think-tank, Niti Aayog, fussy. The story begins with minimal effort ventilators and goes right to man-made reasoning (AI) applications and automaton observed social removing.

For showing up representatives at Fastrack, a messenger organization in Hyderabad, the main purpose of revealing is not the boss, however a computerized warm scanner. It is a dystopic scene. Veiled representatives stand vis-à-vis before a robot that records temperatures. Such screening is fundamental to getting the coronavirus disease early.

So also, Gurugram-based Staqu Technologies has introduced AI-empowered warm imaging cameras for screening basic administrations laborers in Punjab and Uttar Pradesh. Staqu Technologies' worked in warm gadget can quantify internal heat level from up to 10 meters and prints laborers' entrance passes.

Asimov Robotics' "Karmi-bot" is trialling medication apportioning obligations at disconnection wards in emergency clinics. It can even lead video calls with guardians. "These are only a couple of the trend-setters who are taking the battle to the pandemic," said Kant. [1]

In India's Covid-19 fightback, huge information experts sit quietly at the backside. "Information and innovation are the greatest warriors in the battle against Covid-19. Furthermore, something they can do is suggest the degree of lockdown on a hyperlocal level in a granular way. Such a degree of complex dynamic is difficult to utilize information," says Ashwin Srivastava, the CEO of Sapio, an AI arrangements firm. The specialists have cut up the nation's locale into hotspots, non-hotspots, red, orange, and green zones, contingent upon their weakness and Covid-19 case tallies. Sapio Umbrella's lockdown stage, which utilizes enormous information innovation, cases to give an ideal arrangement to lockdowns, down to the town level that can be extrapolated to bigger zones.

\section{APPLICATIONS OF BIG DATA: TRACKING AND DIAGNOSING COVID-19 CASES}

Having a solid, delicate, and explicit demonstrative test is of vital significance in the avoidance and control of irresistible issue. Scientists have prevailing with regards to setting up a sub-atomic unit ready to catch the best possible determination and recognize COVID-19 and SARS-CoV rapidly and precisely. Salivary diagnostics appears to hold extraordinary guarantee in electively identifying the infection. Along with sub-atomic examines and tests, ether multiplex nucleic corrosive enhancement or microarray based, high-goals CT of the chest is central for observing the malady course and its development in terms of seriousness and reaction to treatment. At present continuous examination is likewise attempting to recognize early radiological indicators of anticipation, which would be incredibly useful in defining patients with COVID-19 and in their clinical administration. $[2,3,4]$

Computer based intelligence can encourage the finding of COVID-19 cases. For example, deduce vision is a beginning up that utilizes profound learning clinical imaging stages for encouraging brisk finding of COVID-19 cases by means of the acknowledgment of explicit lung highlights. [2,3]

Moreover, square chain innovation is a novel decentralized arrangement of recording, confirming, and endorsing information and doing a progression of exchanges. It is described by an elevated level of security and empowers the conveyance of patient-focused medicinal services administrations, improved general wellbeing reconnaissance, the board of flare-ups and a brisk and elective dynamic procedure. An ease square chain and AI-coupled self-testing and following framework has been proposed for dealing with the COVID-19 pandemics, in created settings (to abstain from overpowering and stressing general wellbeing limit and medicinal services/research facility foundation) and in creating, asset constrained settings.[5,6]

\section{DIGITAL TECHNOLOGIES COMES WITH PRIVACY CONCERNS}

There are developing security worries about the manner in which's administrations use information to react to the COVID-19 emergency. As new innovations develop that plan to accumulate, scatter, and use information to help the battle against COVID-19, we might want to ensure they regard moral prescribed procedures. Indeed, even in the midst of emergency, we have to consent to information security guidelines and guarantee that the information is utilized morally[12].

there is excitement for utilizing computerized advances, however cautioned that there are not kidding information insurance and human-rights standards associated with gathering data on residents or following their developments, and that we should never step past the standards of individual opportunities and rights. An option in contrast to governments utilizing their forces to get hold of information gathered by tech organizations is to urge residents to deliberately introduce applications for non-benefit research purposes and give information from cell phones, wellness trackers and other cell phones. With present-day innovation for gathering and crunching information, there is extraordinary guarantee in utilizing inventive, information driven devices to battle the infection. In any case, systematizing huge scope resident information assortment frameworks is a perilous way that could prompt meddlesome practices from which it will be hard to remember our means.[10] 
As large information will be basic for dealing with the COVID-19 pandemic in the present advanced world, the conditions for dependable information assortment and handling at an overall scale must be clear. We contend that the use of carefully accessible information and calculations for forecast and observation-e.g., recognizing individuals that have ventured out to regions where the sickness has spread or following and secluding the contacts of contaminated individuals - is of vital significance in the battle against the COVID-19 pandemic. It is similarly significant, be that as it may, to utilize these information and calculations in a capable way, in consistence with information assurance guidelines and with due regard for security and privacy. Neglecting to do so will subvert open trust, which will make individuals more averse to follow general wellbeing guidance or proposals and bound to have less fortunate wellbeing outcomes [7]. Cautious information the executive's practices ought to administer the two-information assortment and handling. In the assortment of information from influenced individuals, the guideline of proportionality ought to apply, which implies that the information assortment must (I) be relative to the earnestness of the general wellbeing danger, (ii) be restricted to what's important to understand a chose general wellbeing goal, and (iii) be logically supported. Accessing information from individual gadgets for contact following purposes, for example, are regularly legitimized in the event that it happens inside explicit limits, includes a reasonable reason-e.g., cautioning and separating individuals that may are presented to the infection-and no less-obtrusive other option-e.g., utilizing anonymized versatile situating information-is appropriate for that reason. Moreover, 'do it without anyone's help' wellbeing reconnaissance, as it was marked by the Italian information insurance authority, ought to be maintained a strategic distance from.

At the information preparing level, information quality and security controls are required. Information respectability shortcomings, which are basic when information from individual computerized gadgets are utilized, can present little blunders in one or various components, which progressively can outsized affect enormous scope prescient models. Moreover, information penetrates, deficient or ineffectual de-recognizable proof and predispositions in datasets can become significant reasons for doubt in general wellbeing administrations.

Information protection challenges not exclusively are of a specialized sort yet in addition rely on political and legal choices. Mentioning or justifying access to non-open gadgets can, for purposes like contact following, be less difficult than basically utilizing anonymized versatile situating information. In any case, convincing suppliers to permit access to or even help with decoding cryptographically ensured information (like what happened during the 2016 US Federal Bureau of Investigation-Apple encryption debate) might be counterproductive, particularly if the understandings between (entomb) national specialists and specialist co-ops need straightforwardness or extent. Comparable exchange offs apply to wellbeing applications that need clients to enlist with their names or national recognizable proof numbers. National specialists should be careful that correctly in light of the fact that individual information may contain significant data about the social collaborations and ongoing developments of contaminated individuals, they ought to be dealt with capably. Abrogating assent and security rights inside the name of illness reconnaissance may fuel doubt and at last wind up being disadvantageous. There are reports that China's advanced scourge control may require exacerbated trashing and open doubt. This danger of doubt is considerably more noteworthy in nations in which residents place a much lower level of trust in their legislature, for example, Italy, France, and the USA.[8] In this way, at whatever point access to those information sources is required and is esteemed relative, the general population ought to be enough educated. Mystery about information access and use ought to be maintained a strategic distance from. Straightforward open correspondence about handling for the commonweal ought to be sought after. Information preparing understandings, for instance, ought to uncover which information are transmitted to outsiders and for which reason.

Reports from Taiwan show a promising approach to use large information investigation to react to the COVID-19 emergency without fuelling open question. Taiwanese specialists coordinated their national wellbeing protection database with movement history information from customs databases to help on the off chance that recognizable proof. Different advancements, for example, QR code checking and web-based revealing, were likewise utilized for control purposes. These measures were joined with open correspondence techniques including continuous wellbeing checks and support for those under isolate. [9]

\section{Guidelines still difficult to implement}

Distinguishing the principal powerless networks are frequently significant for wellbeing authorities to control reaction endeavours like wellbeing framework enhancements, crisis subsidizing portion, and deterrent measures. This is particularly significant in the rising nations where day to day environments can bargain one's capacity to follow counsel on the best way to carry on. Washing your hands for 20 seconds or more with clean cleanser is difficult to do when your principle wellspring of water is a dirtied waterway. Self-isolate and self-segregation are unreasonable when you share a solitary live with other relatives. Furthermore, remaining at home is outlandish on the off chance that you live hand to mouth and should go out two times every day to work and afterward stock up for the following feast.

One approach to do that is to set up free moral boards of trustees or information trusts. Their job will be to make information administration instruments to search out the harmony between contending open interests, while securing singular protection. Instances of such standards remember setting up clear rules for the reason and course of events for the utilization of the information, characterizing clear 


\section{International Journal of Engineering Applied Sciences and Technology, 2020 Vol. 5, Issue 4, ISSN No. 2455-2143, Pages 186-190 \\ Published Online August 2020 in IJEAST (http://www.ijeast.com)}

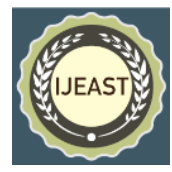

procedures for the entrance, preparing, and end of utilization of individual information toward the finish of the emergency.

\section{RESULT AND DISCUSSION}

The assortment of information for the improvement of general wellbeing is exceptionally noteworthy yet it is raising the danger for open security. An application like Arogya setu which is currently carefully forced by the administration is a major danger to security. These applications are presently totally following an individual's development, search history and the primary concern is these applications are completely constrained by the legislature and the danger is that open information could use for political advantage. The one more danger we found that information could be hacked by different nations and can cause digital assault like exercises. These applications accumulate data through wearables, facial acknowledgment, or through receivers. Wearables gather information about wellbeing, facial acknowledgments can follow while an individual in dissent and receivers are persistently listening encompassing voices.

\section{CONCLUSION}

Enormous information is amazing. In any case, with extraordinary force comes incredible duty. While we approach this enormous database of data, there will consistently be some vulnerable sides and missing factors of information that keep us from having the full picture.

In the best possible setting, enormous information can be unfathomably valuable. Be that as it may, to outfit its full force, we have to have the two individuals who know about information models just as individuals who comprehend the study of disease transmission and the clinical ramifications of the infection to cooperate.

It is imperative to remember that current enormous information models might be deficient because of factors that remain unaccounted for, (for example, populace thickness), either because of factual or methodological confinements, or in light of the fact that the applicable factors have not yet been recognized. This implies notwithstanding our earnest attempts, we may at present be feeling the loss of the whole picture on COVID-19.

Actually, prescient examination is only that: prescient, not fortune-telling. Yet, the more data we put into existing models, the more exact our understandings will be. That will require social insurance laborers, policymakers, information researchers and disease transmission experts all cooperating to join what they know and give the most exact picture conceivable.

As the world supports itself for the effect of the COVID-19 episode, it is imperative to recollect that innovation is only the total development of humankind after some time, and in innovation we've the apparatuses important to help us endure and ensure ourselves. We don't have a clue what lies future for us inside the coming many months, yet we'll confront it together, and our most noteworthy quality will be by the way we share, examine, and get bits of knowledge from our mutual information. With the best possible innovation applied inside the correct heading, we've the possibility to contain and limit effect of infection today and inside what is to come.

The COVID-19 pandemic is an overwhelming test for the world and requires a phenomenal and composed reaction. The emergency calls for us to exhibit our common humankind and we should put forth sure that our attempts to battle the infection are not incidentally disintegrating individuals' privileges.

\section{ACKNOWLEDGEMENT}

This paper and the examination behind it would not have been conceivable without the uncommon help of my companion vinod joshi. His energy, information and demanding meticulousness have been a motivation and kept my work on target from my first experience with the information assortment about the point to the last draft of this paper. I am likewise appreciative for the adroit remarks offered by the mysterious companion analysts at Texts. The liberality and aptitude of everyone has improved this investigation in endless manners and spared me from numerous blunders; those that definitely remain are altogether my own duty.

\section{REFERENCES}

1 Business Insider,

https://www.businessinsider.in/education/news/indi as-think-tank-niti-aayog-is-making-ai-simple-andfun-for-2-5-millionstudents/articleshow/74365745.cms

2 Wong, Z.S.Y.; Zhou, J.; Zhang, Q. (2019) Artificial Intelligence for infectious disease Big Data Analytics. Infect. Dis. Health, 24, 44-48.

3 McCall, B. (2020) COVID-19 and artificial intelligence: Protecting health-care workers and curbing the spread. Lancet Digit. Health, 2, e166e167.

4 Ai, T.; Yang, Z.; Hou, H.; Zhan, C.; Chen, C.; Lv, W.; Tao, Q.; Sun, Z.; Xia, L. (2020) Correlation of Chest CT and RT-PCR Testing in Coronavirus Disease 2019 (COVID-19) in China: A Report of 1014 Cases. Radiology.

5 Mashamba-Thompson, T.P.; Crayton, (2020) E.D. Blockchain and Artificial Intelligence Technology for Novel Coronavirus Disease-19 Self-Testing. Diagnostics, 10, 198

6 Chattu, V.K.; Nanda, A.; Chattu, S.K.; Kadri, S.M.; Knight, A.W. (2019) The Emerging Role of Blockchain Technology Applications in Routine Disease Surveillance Systems to Strengthen Global Health Security. Big Data Cogn. Comput. 2019, 3, 25 . 
Published Online August 2020 in IJEAST (http://www.ijeast.com)

7 Ward, (2017). P. R. Front. Public Health 5, 22-22.

8 OECD. https://www.oecd.org/gov/government-at-aglance22214399.htm.

9 Wang, C. J., Ng, (2020) C. Y. \& Brook, R. H. JAMA https://doi.org/10.1001/jama.2020.3151
10 Ienca, M. \& Vayena, E. Nat Med. (2020) https://doi.org/10.1038/s41591-020-0832-5.

11 Mittelstadt, B., Benzler, J., Engelmann, L.(2018) Prainsack, B. \& Vayena, E. Life Sci. Sci. Pol. 14, 9.

12 (Zaimova, 2020) https://www.weforum.org/agenda/2020/03/roledata-fight-coronavirus-epidemic 